model that we in the United Kingdom would do well to adapt is the standard of care advocated last year by the National Advisory Council for Human Genome Research of offering genetic tests only as part of a research protocol. ${ }^{5}$

\section{THERESA MARTEAU}

Director

SUSAN MICHI

Research fellow

Psychology and Genetics Research Group,

United Medical and Dental Schools of

Guy's and St Thomas's Hospitals,

Old Medical School Building.

Guy's Campus,

London SE1 9RT

1 Ryan MP, French J, Al-Mahdawi S, Nihoyannopoulos P, Cleland JGF, Oakley CM, et al. Genetic testing for familia hypertrophic cardiomyopathy in newborn infants: an ethical hypertrophic cardiomyopathy in newborn infants: an ethical
debate. [Commentaries by P S Harper, A Clarke; J Davis; L Grigg.] BMF 1995;310:856-9. (1 April.)

L Grigg.] $B M 7$ 1995;310:856-9. (1 April.)
2 Michie S, McDonald V, Marteau TM. Understanding responses to predictive genetic testing: a grounded theory approach Psychology and Health (in press).

3 Wiggins S, Whyte P, Huggins M, Adam S, Theilmann J, Sheps $\mathrm{SB}$, et al. The psychological consequences of predictive testing for Huntington's disease. $N$ Engl $f$ Med 1992;327: $1401-5$.

4 Lynch HT. DNA screening for breast/ovarian cancer susceptibility based on linked markers - a family study. Arch Intern Med 1993;153:1979-87.

5 National Advisory Council for Human Genome Research. Statement on use of DNA testing to presymptomatic identification of cancer risk. IAMA 1994;271:785.

\section{Dosage of angiotensin converting enzyme inhibitors}

EdrTor,-A L Clark and A J S Coats highlight the common problem of suboptimal doses of angiotensin converting enzyme inhibitors being prescribed for patients with impaired left ventricular function.' Their paper, however, contains an important error, and when this is corrected the situation is seen to be even worse than they state.

Clark and Coats suggest that the optimum dose of captopril to reduce mortality is $25 \mathrm{mg}$ twice daily. This is not the case. The study they cite in support of this dose did not show a significant reduction in mortality. The dose of captopril most clearly shown to reduce mortality is $50 \mathrm{mg}$ three times daily, and most studies of heart failure showing an improvement in symptoms and exercise tolerance with captopril have used doses at least as large as this. ${ }^{23}$

OHN MCMURRAY

Department of Cardiology,

Western General Hospital

Edinburgh EH4 2XU

1 Clark AL, Coats AJS. Severity of heart failure and dosage of angiotensin converting enzyme inhibitors. BMf 1995;310: 973-4. (15 April.)

\section{Consultants' workload in outpatient clinics}

\section{Not all specialist groups hold outpatient clinics}

EDrToR,-David Armstrong and Mick Nicoll suggest that the number of outpatients seen per hospital doctor and whole time consultant equivalent declined steadily from the inception of the NHS in 1949 until 1991.' The implication seems to be that there are increasing inefficiencies in the hospital sector and that the present push for more consultants in service may be necessary. A few of the assumptions made in this study are (1) that the specialty mix of consultants has not altered since 1949 , (2) that consultants see outpatients, and (3) that the practice of medicine has not changed.

During the 12 years of my career in medicine I have seen major changes in numbers of consultant staff in anaesthesia $(+359)^{2}$ and accident and emergency $(+73) .{ }^{2}$ When the NHS first developed these specialties and radiology, pathology, and public health medicine were in their infancy. The published figures for December 1992 for England and Wales show that $30 \%$ (5499) of the practitioners eligible for distinction awards (that is, consultants (total 17662)) were in these "new" specialties. These specialists do not hold outpatient clinics and therefore do not seem to be working, according to this study.

The complexity of care now offered to patients has increased. In the $1940 \mathrm{~s}$ the list of medical and surgical treatments available to doctors was limited. Many patients consulted and were advised rather than than treated. Doctors now perform endoscopies, arterial catheterisations, operations, and other complex procedures on an outpatient as well as an inpatient basis. These interventions require skilled staff and do not appear in the data used for this study.

Given the growth in the complexity of medicine over the past $\mathbf{5 0}$ or so years, it is naive to suggest that by dividing the number of patients seen as outpatients by the number of consultants employed by the NHS one can derive a meaningful statistic that is a measure of inefficiency in the hospital service. Accident and Emergency Department Accident and Emergency Depal Hallamshire Hospital Rheffield S10 2JF

1 Armstrong D, Nicoll $M$. Consultants' workload in outpatien clinics. BMf 1995;310:581-2. (4 March.)

Allen P. Medical and dental staffing prospects in the NHS in England and Wales 1990. Health Trends 1991-2;23:132-40.

Advisory Committee on Distinction Awards, Department of Health. Distinction awards: analysis of type of award, specialt and percentage distribution at 31 December 1992-England and Wales. Health Trends 1993:25:152.

\section{Consultants spend more time with each patient than in the past}

EdrToR,-David Armstrong and Mick Nicoll's analysis of consultants' workload in outpatient clinics fails to address some important issues. Clearly, the routinely collected English statistics do suggest a decrease in the number of new and old patients seen per consultant per year. This aspect of the consultants' workload cannot, however, be accurately summarised on the basis of a single performance indicator or considered in isolation from other hospital duties.

More obviously, medical technology has expanded exponentially since 1949 . The number of effective drugs has increased from a few dozen in 1949 to almost 1000 in $1991^{2}$ while the list of medical investigations and surgical treatments has mushroomed. What a hospital doctor had to offer a patient with heart failure in 1949 pales into insignificance when compared with what can be offered today.

Secondly, patients are, rightly, becoming more demanding and expecting more explanation. Today's doctors are increasingly offering to share knowledge and decision making, which is in keeping with changing medical education. ${ }^{3}$

Thirdly, health promotion is now part of most doctors' vocabulary, given that many of the government white papers call on all health care professionals to promote health as well as to treat illness.

These three factors alone will ensure that more time will be spent per patient, a point the authors gloss over in their conclusion that "work with new outpatients has declined throughout the period under review." Surely, the former trend is a good thing. The patients' charter now requires that all new outpatients be seen by a consultant, which ensures that the consultants' workloads will expand still further.

The authors' analysis also overlooks the large degree of specialisation that has occurred and the huge variation in the number of new and old patients seen per clinic by specialty (for example, three new patients per consultant in psychiatry versus 140 return patients in an anticoagulant clinic).

Finally, the authors criticise the proposal to expand the number of consultants despite the evidence that historically there has been a persistent underprovision of consultants per capita in Britain compared with most other Western countries. ${ }^{5}$

When trying to "locate health service problems" it may be more fruitful to examine fundamental causes of human behaviour across all professional scales from management through medical and nursing to clerical staff, both within and outside the hospital sector. This should focus on the structure and organisation of health services and the underlying structures of professional education and remuneration.

HELENE IRVINE Registrar in public health medicine Department of Public Health Medicine,

Greater Glasgow Health Board,

Glasgow G2 4JT

Department of Medicine for the Elderly,

Consultar

Department of $M$

Glasgow G21 3UW

1 Armstrong D, Nicoll M. Consultants' workload in outpatient clinics. BMf 1995;310:581-2. (4 March.)

2 BMA and Royal Pharmaceutical Society of Great Britain. British National Formulary (no 22). London: BMA and RPSGB, 1991.

3 Morgan M. The doctor-patient relationship. In: Patrick DL Scambler G, eds. Sociology-as applied to medicine. London: Baillière Tindall, 1988:56-70.

4 Department of Health. The health of the nation: a strategy for health in England. London: DoH, 1992.

5 World Health Organisation. World health statistics. Geneva: WHO, 1988

\section{Quality of care has improved}

EDrToR,-We wish to suggest an alternative interpretation of the data presented by David Armstrong and Mick Nicoll. ${ }^{1}$ During the 20 years 1971-91 the rate of increase in the numbers of general practitioners and consultants was similar (their figure 1). During the same period the rate of new referrals to outpatient clinics rose more slowly. Hence new referrals of outpatients per general practitioner and per consultant fell. This reflects the fact that general practitioners do more for their patients without referring them to hospital (for example, they do minor operations and hold asthma and diabetes clinics) and that consultants do more for their patients at each outpatient consultation (for example, they hold one stop diagnostic clinics and manage patients with asthma, diabetes, and heart failure, who would have required admission, often for several weeks, 25 years ago).

This means that it is inappropriate to equate a fall in numbers of new outpatients per consultant with a "progressive reduction in clinical workload" or "declining productivity." On the contrary, contemporary developments spring from a determination among doctors to provide high quality care as expeditiously and conveniently as possible; this is reflected by the increase in activity in general practitioners' surgeries and hospital clinics. The development of guidelines and protocols for primary and secondary care exemplifies a concern that care should be uniformly of a high quality. The concept of ambulatory care centres extends the role of the hospital towards the community. These centres are likely to prove more equitable and cost effective in providing expert care than the outreach clinics mentioned by Armstrong and Nicoll, particularly when the current inequalities in purchasing are resolved.

Many general practitioners and consultants have become increasingly involved in teaching and 
training, administration and management, and audit and research aside from inpatient care and day surgery. This emphasises that, for all practitioners, workload-when quality as well as quantity is included-has increased over recent years.

B D W HARRISON Consultant physicia

D N L RALPHS Consultant surgeon

Norfolk and Norwich Health Care NHS Trust,

Norwich,

Norfolk NR1 3SR

1 Armstrong D, Nicoll M. Consultants' workload in outpatient clinics. BMf 1995;310:581-2. (4 March.)

\section{One cause for the decline may be the fall in senior junior staff}

EDrToR,-David Armstrong and Mick Nicoll do not provide any evidence to justify their assertion that the average consultant saw 1680 new patients in $1949,{ }^{1}$ a year in which the combined number of whole time specialist senior hospital medical officers and senior registrars exceeded the number of whole time consultants. ${ }^{2}$ It would be naive to believe that these staff did not have an importan role in seeing outpatients. Since then the ratio of such senior junior staff to consultants has fallen to $1: 3$. The implication that because of this calculated reduction in consultants' average outpatien workload sufficient resources are available to meet the demands for additional outreach clinics without expansion in the number of consultants needs to be tested for the individual specialties concerned. For example, in 1949, 10.5 new dermatological patients were seen per clinic $^{2}$-not, I suggest, very different from the situation today.

W M SEYMOUR

Brook General Hospital

London SE18 4LW

1 Armstrong D, Nicoll M. Consultants' workload in outpatien clinics. $B M f$ 1995;310:581-2. (4 March.)

Ministry of Health. Report. London: HMSO, 1949. (Cmd 8342.) 3 Department of Health. Health and personal social services statistics. London: HMSO, 1972-94.

\section{Psychiatry has restructured its service delivery}

EdrTor,-David Armstrong and Mick Nicoll look at changes in consultants' workload in outpatien clinics since 1949. ${ }^{1}$ The delivery of services in psychiatry has been completely restructured since then: it is now community based, with each consultant responsible for a specified population, and large asylums have gradually closed. Beds fell from 148100 in 1954 to 64800 in 1985 , with a final target of 47900 . Simultaneously, annual admissions increased from 78586 in 1955 to 185514 in $1981 .^{2}$ Rather than hold expensive outpatient clinics for everyone, the consultant now heads a busy mutlidisciplinary community team. The team's activity increases annually-including new referrals. A general psychiatrist has 10-12 acute beds for a population of 45000-55000 and diminishing facilities for long term patients. Close liaison with primary health care teams is essential, and only referrals that fulfil the Audit Commission's criteria for severe illness (psychosis, organic disease, or recent discharges) are accepted. ${ }^{3}$ With subspecialisation, consultants supervise additional teams-for example, the effective deliberate self harm teams. The government, service users, and purchasers do not want asylums for severe mental illness or neurotic patients to be seen by consultants rather than by cost effective counsellors in primary health care teams.

Before drugs, electroconvulsive therapy, and effective short term psychotherapies for severe illness, long term support for people with neurotic

ilness was normal. The challenge for consultants today is to train primary health care teams to recognise and treat mental illness in the community and encourage them to develop case registers and networking. Homicide figures indicate that only a third of mentally disordered patients who commit homicide have been in contact with psychiatric services in the previous year." Suicides could be prevented as two thirds of people who commit suicide have consulted their general practitioner in the preceeding month; only a quarter are psychiatric outpatients. Suicide statistics are difficult to interpret: they peaked in 1936 for males, had fallen by 1946 , and in 1986 were similar to those in $1946 .^{5}$

We need to monitor whether the Health of the Nation's targets can be met by closer supervision of those at risk. If severely ill patients are known to, and monitored by, the service, with shared care, when a relapse occurs prompt care can be given. Appropriate skill mixes and case mixes allow consultants to manage the whole population efficiently and effectively, using their own skills to assess risk and treat resistant patients with sophisticated regimens, attend care programme meetings, and provide reports. Supervision of staff is more onerous as no case referred is now straightforward. With the care programme approach and supervision registers we carry responsibility for everyone referred, and increasingly for the total population served. Consultants are expected to give time to planning mental health strategy, including community facilities.

JANET BRUCE

Derby City General Hospital,

Southern Derbyshire Mental Health Trust

Derby DE22 3NE

1 Armstrong D, Nicoll M. Consultants' workload in outpatien clinics. BMf 1995;310:581-2. (4 March.)

2 Thornicroft G, Bebbington P. De-institutionalisation-from hospital closure to service development. Br f Psychiatry 1989;155:739-53.

Audit Commission. Finding a place. A review of mental health services for adults. London: HMSO, 1994.

4 Boyd W, and steering committee. Confidential inquiry into homicides and suicides by mentally ill people. A preliminary report
on homicide. London: Steering Committee of Confidential In houry, 1994.

5 Farmer RDT. Suicide and poisons. Hum Psychopharmacol 1994;9:S11-9.

\section{Existing outpatient services could be more efficient}

EdrTor,-David Armstrong and Mick Nicoll suggest that patients are being retained in the outpatient system unnecessarily and that in recent years recycling of patients has worsened, thereby blocking access for new referrals. ${ }^{1}$ They also suggest that an increase in the number of consultants would solve demand for outreach clinics in general practice despite the fact that hospital consultants have been seeing a declining number of new patients.

Recently we audited our general medical outpatient clinic because the doctors' workload was increasing steadily owing to rising numbers of patients. This was causing the clinics to overrun and making it difficult to accommodate urgent referrals. We analysed the patient content of the clinic and assessed the efficiency of patients' management. We found that the number of new patients attending the clinic exceeded the number being discharged and that a considerable number of patients were returning to the clinic for review of their management only and had been attending for several years. They also tended to have been seen by the more junior members of the team.

To address the problem, return patients are now seen by senior doctors, who assess them with a view to discharge. New patients may be seen at first by more junior doctors but, in accord with the patient's charter, see a consultant at their second attendance. All members of the team meet after the clinic to formulate a management plan for each patient, and these meetings form part of the training for senior house officers. Since the introduction of the new regimen two months ago the number of patients discharged has been twice the number of new patients seen, which is a reversal of the trend identified in the original audit (table).

Numbers of new patients attending outpatient clinic and discharged from clinic at initial audit and after change in policy

\begin{tabular}{lccc}
\hline & $\begin{array}{c}\text { New } \\
\text { patients }\end{array}$ & $\begin{array}{c}\text { Discharged } \\
\text { patients }\end{array}$ & Change \\
\hline $\begin{array}{l}\text { Four clinics audited early } \\
\quad 1994\end{array}$ & 30 & 14 & 16 \\
$\begin{array}{l}\text { Seven clinics monitored late } \\
1994 / \text { early 1995 }\end{array}$ & 41 & 92 & -51 \\
\hline
\end{tabular}

Our experience suggests that, initially, effort might more usefully be concentrated on improving the efficiency of existing outpatient clinics to provide a more expeditious service for referrals from general practitioners rather than hastening to appoint additional consultants in outreach clinics.

TRUDIE ROBERTS Consultant physician, general medicine A M HEAGERTY Consultant physician, general medicin PAULA FOSTER Acting assistant trust clinical audit coordinator

University Hospital of South Manchester, Manchester M20 2LR

1 Armstrong D, Nicoll M. Consultants' workload in outpatient clinics. $B M F$ 1995;310:581-2. (4 March.)

\section{Consultants may be seeing many new patients since 1991}

EDITOR,-David Armstrong and Mick Nicoll show that the average number of new patients seen by a consultant has declined steadily from 1680 in 1949 to 618 in $1991 .^{1}$ They conclude that the "inefficiencies" in the health service are due mainly to the declining productivity in the hospital sector rather than in general practice and even suggest that consultants might have attempted to divert attention away from their declining workload in outpatient clinics by holding general practitioners responsible for the inefficiencies. They express concern that, despite these data, since the NHS reforms of 1991 the outpatient problem is beginning to be redefined in terms of a need for yet more consultants.

While appreciating their concern, we believe that caution is necessary in drawing conclusions by extrapolating from the historical trend of referral rates to the present, reformed NHS. Data on our ear, nose, and throat service between August 1990 and July 1994 at Horton General Hospital showed a rapid $(70 \%)$ increase in the number of new referrals seen in the clinic under the supervision of a single consultant without any increase in the number of clinics (table). This increase occurred despite the fact that during that period we introduced a direct referral system for tonsillectomy and another one for hearing aids so that some new referrals bypassed the clinic.

While we cannot generalise the increase in our workload of new referrals to other specialties, we believe that the general trend in the rate of new

Numbers of new referrals and patients followed up in ear, nose, and throat outpatient clinic, August 1990 to fuly 1994

\begin{tabular}{lccc}
\hline & $\begin{array}{c}\text { New } \\
\text { referrals }\end{array}$ & $\begin{array}{c}\text { Patients } \\
\text { followed up }\end{array}$ & $\begin{array}{c}\text { Total } \\
\text { seen }\end{array}$ \\
\hline Aug 1990-Jul 1991 & 766 & 933 & 1688 \\
Aug 1991-Jul 1992 & 1024 & 998 & 2022 \\
Aug 1992-Jul 1993 & 1224 & 856 & 2080 \\
Aug 1993-Jul 1994 & 1225 & 844 & 2069
\end{tabular}

